\title{
Correction to: A gaze-based interactive system to explore artwork imagery
}

\author{
Piercarlo Dondi ${ }^{1}\left([) \cdot\right.$ Marco Porta $^{1}(\mathbb{D}) \cdot$ Angelo Donvito $^{2} \cdot$ Giovanni Volpe $^{3}$
}

Published online: 31 May 2021

(c) The Author(s) 2021

\section{Correction to: Journal on Multimodal User Interfaces https://doi.org/10.1007/s12193-021-00373-z}

Due to an error not dependent on the authors, the affiliation of Angelo Donvito was wrongly indicated as "COMITES srl, via Cifra 29, 20159 Milano, Italy”; the correct affiliation is instead "My Smart s.r.1., Via delle Officine s.n., 75100, Matera, Italy".

Original article corrected.

Publisher's Note Springer Nature remains neutral with regard to jurisdictional claims in published maps and institutional affiliations.

The original article can be found online at https://doi.org/10.1007/ s12193-021-00373-z.

$\triangle$ Piercarlo Dondi

piercarlo.dondi@unipv.it

Marco Porta

marco.porta@unipv.it

Angelo Donvito

angelo.donvito@mysmart-italia.it

Giovanni Volpe

volpe@comites.mi.it

1 Department of Electrical, Computer and Biomedical Engineering, University of Pavia, Via Ferrata 5, 27100 Pavia, Italy

2 My Smart s.r.l., Via delle Officine s.n., 75100 Matera, Italy

3 COMITES srl, via Cifra 29, 20159 Milano, Italy 